\title{
Taurine Induces a Long-Lasting Increase of Synaptic Efficacy and Axon Excitability in the Hippocampus
}

\author{
Mario Galarreta, ${ }^{1}$ Julián Bustamante, ${ }^{2}$ Rafael Martín del Río, ${ }^{1}$ and José M. Solís ${ }^{1}$ \\ ${ }^{1 S e r v i c i o ~ d e ~ N e u r o b i o l o g i ́ a, ~ D e p a r t a m e n t o ~ d e ~ I n v e s t i g a c i o ́ n, ~ H o s p i t a l ~ R a m o ́ n ~ y ~ C a j a l, ~} 28034$ Madrid, and 2Departamento \\ de Fisiología, Facultad de Medicina, Universidad Complutense, 28040 Madrid, Spain
}

The physiological role of taurine, one of the most abundant free amino acids in the mammalian brain, is still poorly understood. We have found that bath application of the amino acid taurine induces two opposite actions on field excitatory synaptic potentials (fEPSP) recorded in the CA1 area of hippocampal slices: a decrease in fEPSP slope prevented by $\mathrm{GABA}_{\mathrm{A}}$ antagonists, and a long-lasting potentiation of fEPSP independent of $\mathrm{GABA}_{\mathrm{A}}$ or NMDA receptor activation. Two long-lasting processes account for this taurine-induced potentiation: (1) an increase in synaptic efficacy that is accompanied neither by modifications in the basic postsynaptic membrane electrical properties nor by those presynaptic changes involved in fEPSP paired-pulse facilitation; and (2) an increase in the axon excitability revealed by a reduction in the threshold for antidromic action potential activation. In addition, taurine perfusion also induces a long-lasting increase in intracellularly recorded EPSPs and monosynaptically activated IPSPS. A number of experimental observations such as temperature dependence, extracellular $\mathrm{Na}^{+}$concentration dependence, and saturation studies, although they are not unequivocally conclusive, suggest that the taurine uptake system is required for the taurineinduced fEPSP potentiation. Our data describe a new taurine action defined as a potentiation of synaptic transmission due in part to an increment in presynaptic axon excitability and in synaptic efficacy.

Key words: taurine; axon excitability; long-lasting synaptic potentiation; EPSP; IPSP; fiber volley; taurine uptake; hippocampal slices
In mammalian brain, taurine (2-aminoethane sulfonic acid) is one of the most abundant frec amino acids, gencrally only cxcecded in concentration by glutamate (for review, see Huxtable, 1989). At cellular levels, specific antibodies against taurine have shown that this amino acid is present in neurons, where it is localized in soma, dendrites, axons, and synaptic terminals, and also in glial cells (Ottersen et al., 1985; Ottersen, 1988; Torp et al., 1992; Nagelhus et al., 1993). Although taurine is ubiquitously and highly concentrated in the brain, its physiological role is still poorly understood. Moreover, it is not a protein component and it is not involved in any metabolic pathway (Huxtable, 1992).

One of the first proposals of taurine function in the brain is its role as an inhibitory neurotransmitter. This assumption is based mainly on the observations that its exogenous application induces inhibition of neuronal firing in different structures (for review, see Huxtable, 1989), that it is localized in synaptic terminals (Lombardini, 1976), and that a high affinity uptake system has been demonstrated for taurine (Lombardini, 1978; Liu et al., 1992). However, taurine lacks two main properties to be clearly accepted as a neurotransmitter: (1) it is released by depolarization mainly in a calcium-independent way (Hanretta and Lombardini, 1986; Pasantes-Morales et al., 1988); and (2) so far the existence of a specific taurine receptor has not yet been demonstrated

\footnotetext{
Received Aug. 18, 1995; revised Sept. 15, 1995; accepted Sept. 19, 1995.

This work was supported by a grant from the "Fondo de Investigaciones Sanitarias de la Seguridad Social" (93/0565). M.G. was supported by a fellowship from "Dirección General de Investigación Cientifica y Técnica." We thank Drs. R. A. Nicoll, D. Kullmann, and N. Menéndez for helpful discussions and Dr. R. J. Huxtable for his generous gift of GES. We also thank A. Latorre for technical assistance and S. McGrath and J. Sealine for editorial help.

Correspondence should be addressed to José M. Solís, Ph.D., Servicio de Neurobiología, Departamento de Investigación, Hospital Ramón y Cajal, Ctra. de Colmenar Km 9, 28034 Madrid, Spain.

Copyright $\mathbb{C} 1995$ Society for Neuroscience $0270-6474 / 95 / 160092-11 \$ 05.00 / 0$
}

(Huxtable, 1989). Moreover, its reported neuroinhibitory action in somc arcas is not spccific, bccausc it can bc cxplaincd by the activation of $\mathrm{GABA}_{\mathrm{A}}$ or glycine receptors, as judged by the inhibition of the taurine action by specific antagonists for both receptors (Okamoto and Sakai, 1981; Horikoshi et al., 1988; Lewis et al., 1991).

Taurine also has been proposed as an inhibitory neuromodulator, because it regulates calcium fluxes in brain nerve terminals (Kuriyama et al., 1978; Pasantes-Morales and Gamboa, 1980; Namima et al., 1983). In this sense taurine has been shown to reduce the release of several neurotransmitters, such as noradrenaline and acetylcholine from cortical slices and brain synaptosomes (Kuriyama et al., 1978), GABA from cerebellar slices (Namima et al., 1983), and aspartate, glutamate, and GABA from cortical synaptosomes (Kamisaki et al., 1993).

Although hippocampal slices are well suited preparations for studying the electrophysiological action of a neuroactive substance, few studies within this structure have been done that show that taurine induces an increase in chloride permeability in pyramidal and granule cells (Zeise, 1985; Taber et al., 1986). There are no reports even testing whether $\mathrm{GABA}_{\mathrm{A}}$ antagonists affect this taurine action. Studies on other possible actions of taurine on synaptic potentials are lacking. Thus, our aim has been to assess these two issues in the CA1 area of hippocampal slices. We have found that taurine inhibitory action is antagonized by $\mathrm{GABA}_{\mathrm{A}}$ receptor inhibitors and, even more importantly, that taurine induces a long-lasting potentiation of synaptic transmission. This last result is evidence of a completely new action of taurine, which we are going to study in this paper.

\section{MATERIALS AND METHODS}

Preparation of slices. Experiments were performed on transversc hippocampal slices $(400-500 \mu \mathrm{m})$, obtained from adult female Sprague- 
Dawley rats (200-250 gm), by standard procedures. Briefly, after the rat was decapitated, its brain was rapidly removed and dropped into ice-cold standard medium (in $\mathrm{mM}$ ): $\mathrm{NaCl} 119, \mathrm{NaHCO}_{3} 26.2, \mathrm{KCl} 2.5, \mathrm{KH}_{2} \mathrm{PO}_{4} 1$, $\mathrm{MgSO}_{4} 1.3, \mathrm{CaCl}_{2} 2.5$, and glucose 11 pregassed with $95 \% \mathrm{O}_{2} / 5 \% \mathrm{CO}_{2}$. Then the hippocampi were dissected from the surrounding tissue, and transversal slices were cut by a manual chopper. Before recording, the slices were maintained in an interface holding chamber (Nicoll and Alger, $1981)$ at room temperature $\left(21-25^{\circ} \mathrm{C}\right)$. After at least $1 \mathrm{hr}$, a slice was transferred to a submersion-type recording chamber (Nicoll and Alger, 1981) and continuously perfused (flow rate $1.5-2 \mathrm{ml} / \mathrm{min}$ ) with the standard medium equilibrated with $95 \% \quad \mathrm{O}_{2} / 5 \% \quad \mathrm{CO}_{2}$. Experiments were performed at $30-32^{\circ} \mathrm{C}$, unless otherwise indicated.

Solutions. Drugs applied by addition to the standard perfusion solution included taurine, $\beta$-alanine, GABA, bicuculline methiodide (BMI), picrotoxin, D,L-2-amino-5-phosphonovaleric acid (APV), tetrodotoxin (TTX), 4-aminopyridine (4-AP), $N$-methyl-D-glucamine chloride (all from Sigma, St. Louis, MO), $N$-methyltaurine (NM-TAU) (Merck, Darmstadt, Germany), 6-cyano-7-nitroquinoxaline-2,3-dione (CNQX) (Tocris Cookson, Bristol, UK, or Research Biochemicals, Natick, MA), and 2-guanidinoethanesulfonic acid (GES) (gift from Dr. R. J. Huxtable, University of Arizona, Tucson, AZ). The osmolarity of the perfusion solutions before and throughout the experiments were tested by a micro-osmometer (Advanced Instruments Mod.3MO, Norwood, MA).

Extra- and intracellular recordings. To obtain evoked synaptic responses (extra- and intracellular) in the CA1 area, Schaffer collateral-commissural fibers were stimulated with electrical pulses $(0.1-0.3 \mathrm{~mA}, 20-40$ $\mu \mathrm{sec}, 0.05-0.066 \mathrm{~Hz}$ ), applied through bipolar microelectrodes located in stratum radiatum and supplied by a Grass S48 stimulator (Quincy, MA) or a pulse generator A.M.P.I. Mod. Master 8 (Jerusalem, Israel). Evoked extracellular field potentials (fEPSP and FV) from the stratum radiatum of the CA1 region were recorded with low resistance glass micropipettes filled with $2 \mathrm{M} \mathrm{NaCl}$. In some experiments an additional recording micropipette was placed in the pyramidal cell layer to record the population spike (PS). Recording micropipettes were connected to field effect transistors, the outputs of which were filtered between 1 and $3000 \mathrm{~Hz}$ and amplified by an amplifier Grass Mod. 7P511H. Conventional intracellular recordings were obtained using glass micropipettes, filled with $3 \mathrm{M}$ potassium acetate $(70-100 \mathrm{M} \Omega)$ or $3 \mathrm{M} \mathrm{KCl}(40-60 \mathrm{M} \Omega)$. Only cells with a stable resting membrane potential $\left(V_{m}\right)$ higher than $-65 \mathrm{mV}$ and with an apparent input resistance $\left(R_{\mathrm{in}}\right)>40 \mathrm{M} \Omega$ were considered in this study. 'I'he input resistance of the neurons was calculated from the voltage deflection produced by hyperpolarizing current pulses $(0.1-0.3 \mathrm{nA})$ of 50 msec duration. Although in most of the cases the resting potential did not change throughout the experiment, small and aleatory oscillations $( \pm 2$ $\mathrm{mV}$ ) during the washout period were compensated manually when needed.

Evoked EPSPs and monosynaptic IPSPs were recorded in pyramidal cells of the CA1 area with an Axoclamp-2B amplifier (Axon instruments, Foster City, CA). In those experiments (extra- and intracellular) in which $\mathrm{GABA}_{\mathrm{A}}$ antagonists BMI or picrotoxin were present in the bath medium (but not in those experiments in which glutamate antagonists were also included), a cut was made between $\mathrm{CA} 1$ and $\mathrm{CA} 3$, and the concentrations of both $\mathrm{Ca}^{2+}$ and $\mathrm{Mg}^{2+}$ were increased to $4 \mathrm{~mm}$ in the bath medium to prevent epileptiform discharges. In two experiments we observed that these experimental conditions (surgical cut and high concentrations of $\mathrm{Ca}^{2+}$ and $\mathrm{Mg}^{2+}$ ) did not affect taurine effects on fEPSP. Antidromic action potentials in C.A1 and CA3 pyramidal neurons were evoked by stimulating in the alveus or in the CA1 stratum radiatum, respectively. In these experiments, in the presence of CNQX $(20 \mu \mathrm{M})$, APV $(50 \mu \mathrm{M})$, and picrotoxin $(100 \mu \mathrm{M})$ to inhibit cxcitatory and inhibitory synaptic rcsponses, the antidromic responses were identified by their short latencies $(\sim 1.6 \mathrm{msec})$. The threshold of antidromic spike activation throughout the experiment was monitored by changing manually the pulse duration in the pulse generator A.M.P.I. Master 8, which allows a digital control of this parameter.

Data analysis. Evoked responses were digitized at 25 or $100 \mathrm{kHz}$ (TL-1 interface, Axon Instruments), depending on whether we studied synaptic or action potentials, respectively, and stored and analyzed on a 386 IBMcompatible computer using pClamp software (Axon Instruments). The amplitude of the presynaptic FV was measured from the baseline to the negative peak of the FV. For the extracellular experiments, the synaptic strength was calculated using the initial rising slope phase of the fEPSP to avoid contamination of the response by PS. In the intracellular experiments, the maximum amplitude of the synaptic potential or the action potential with respect to the baseline was measured. We considered as baseline the mean value of the signal, taken in a window of $2-5 \mathrm{msec}$, preceding the stimulus artifact. The width of the spike was taken at half of its amplitude. Data were normalized with respect to the mean values of the responses at the $20 \mathrm{~min}$ control period, before the application of taurine. We used a program developed by one of us (J.B.) for these calculations. Traces shown are averages of consecutive responses, the number of which is indicated in every case.

Results are expressed as mean \pm SEM. Statistical differences were assessed by one-way or two-way analyses of variance and two-tailed Student's $t$ tests.

\section{RESULTS \\ Effects of taurine on evoked field potentials}

When taurine, at a concentration of $10 \mathrm{~mm}$, was bath-applied (Fig. $1 A)$ the fEPSP slope was reduced by $30.3 \pm 7.6 \%(n=15)$ after $10 \mathrm{~min}$ of taurine perfusion. Afterwards, still in the presence of the amino acid, the fEPSP slope began to recover and regained control values by approximately the end of taurine perfusion (30 min). During taurine washout, fEPSP slope increased progressively, reaching $67.1 \pm 7.3 \%(n=15)$ over control values at $\sim 15$ min of taurine withdrawal and remained potentiated thereafter for at least $1 \mathrm{hr}$. The fEPSP potentiation was dependent on the taurine perfusion time as illustrated in Figure $1 B$ for the fEPSP values at 15 and $60 \mathrm{~min}$ of taurine washout. Short taurine perfusion time $(10 \mathrm{~min})$ induced a smaller fEPSP potentiation and a faster decay than that observed after a longer time period (30 min). In some experiments $(n=8)$, we were able to record the $\mathrm{FV}$, which is a consequence of the action potentials generated by the electrical stimulation of the Schaffer collaterals axons, and as shown in Figure $1 A$ it increased progressively during taurine perfusion and remained enhanced at least $1 \mathrm{hr}$ after taurine withdrawal $(139.3 \pm 13.0 \%)$. Because the increase in the FV induced by taurine could explain, at least partially, the fEPSP potentiation, we performed a group of experiments $(n=5)$ in which after 15 min of taurine withdrawal, at the time of maximum potentiation, the stimulus strength was reduced until FV amplitude matched the pretaurine amplitude. When this maneuver was performed (Fig. $2 A$ ), it was observed that the fEPSP slope still remained potentiated over control values, and this revealed a component of the taurine-induced fEPSP potentiation that cannot be explained by the increase on FV amplitude. This component is probably a result of an enhancement in synaptic strength. We tested further this component of fEPSP potentiation by studying the stimulus-response curves for FV, fEPSP, and PS in 4 of the 15 experiments described above, in which a series of different intensity stimuli were applied at a frequency of $0.066 \mathrm{~Hz}$ during the control period and at the end of the taurine washout period. These curves (Fig. $2 B$ ) revealed a shift to the left in all cases after $1 \mathrm{hr}$ of taurine washout, indicating that after taurine perfusion larger FV, fEPSP, and PS values were obtained for all of the stimuli used. Supramaximal stimulus intensities, which in the control period evoked no further increase of fEPSP, induced a new ceiling of fLPSP responses after taurine perfusion. This effect could be a result of the increase in the FV, which would recruit more synaptic terminals and therefore increase transmitter release. By plotting fEPSP slopes against FV amplitudes, it could be observed that the taurine-induced fEPSP potentiation was not explained completely by the increase in the FV and that there was a shift to the left and an extra increase of $44.3 \pm 3.7 \%$ over the previous maximal fEPSP values $1 \mathrm{hr}$ after taurine withdrawal (Fig. $2 C$, left). This new gain should occur at some point between the arrival of the action potential to the presynaptic terminal and the generation 


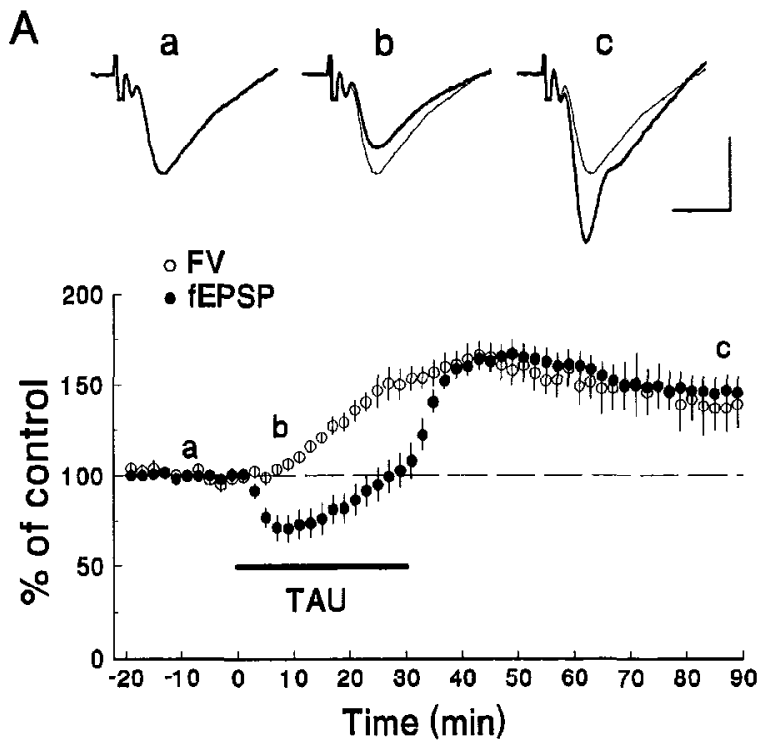

B

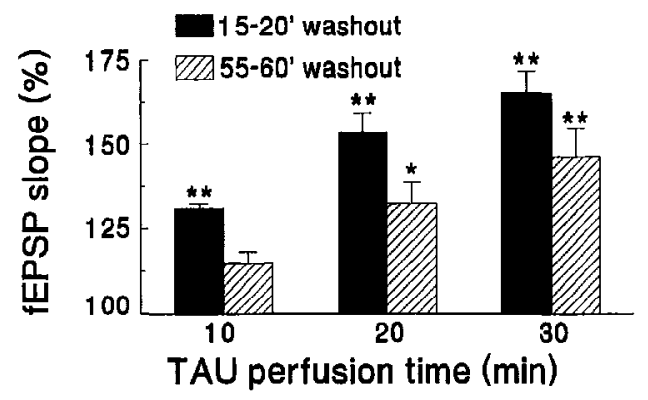

Figure 1. Taurine induces two opposite actions on fEPSPs. $A$, The upper traces show representative averaged $(n-4)$ fEPSPs recorded at three different times ( $a, b$, and $c$ on the graph) during one of the experiments used for the graph. Thin traces in $b$ and $c$ reproduce the control trace in $a$ for comparison. Averages $b$ and $c$ show the decrease and subsequent increase during the first $10 \mathrm{~min}$ of $10 \mathrm{~mm}$ taurine $(T A U)$ application and after $60 \mathrm{~min}$ of washout, respectively. In every evoked potential the stimulus artifact is followed first by the FV and second by the fEPSP. The graph plots summary data that were normalized to the mean value of the 20 min control period and expressed as the mean $\pm \mathrm{SEM} / \mathrm{min}$. Filled circles represent fEPSP slope values $(n=15)$ and open circles represent FV amplitudes from 8 of the 15 experiments in which this potential could be recorded and measured with certainty. For the sake of clarity here and in subsequent figures, points are plotted every $2 \mathrm{~min}$. Here and in subsequent figures black horizontal bars indicate the period of taurine perfusion and horizontal long dashed lines indicate the mean value of the control period before taurine application expressed as $100 \%$. Calibration: $1 \mathrm{mV}$, $5 \mathrm{msec}$. $B$, Histograms represent the mean fEPSP slope values (normalized to the control period) corresponding to 15-20 min (black bars) and 55-60 min (striped bars) after $10 \mathrm{~mm}$ taurine withdrawal, at three different taurine perfusion times ( $10 \mathrm{~min}, n=3 ; 20 \mathrm{~min}, n=3 ; 30 \mathrm{~min}, n=15$ ). Asterisks indicate significative changes $\left({ }^{*} p<0.05 ;{ }^{*} p<0.01\right)$ compared with control values.

of the postsynaptic potential, and it represents an increase in the synaptic efficacy, because a given FV will produce a larger synaptic response after taurine perfusion. On the contrary, a shift to the right could be observed when plotting the PS amplitudes against fEPSP slopes (Fig. $2 C$, right), because after taurine perfusion a larger fEPSP slope was necessary to generate a PS with a similar amplitude as that recorded during the control period.

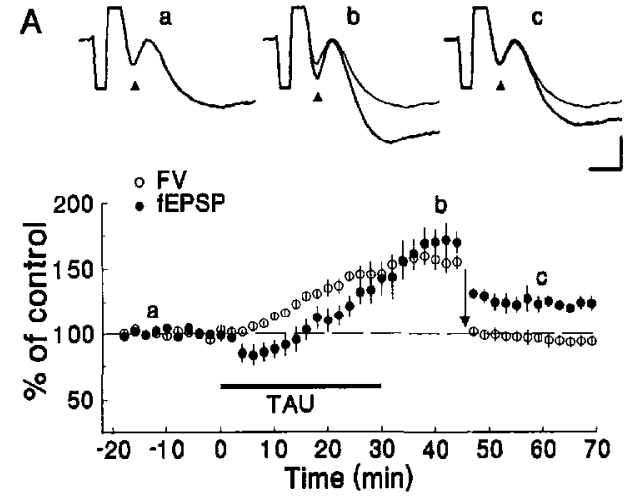

B

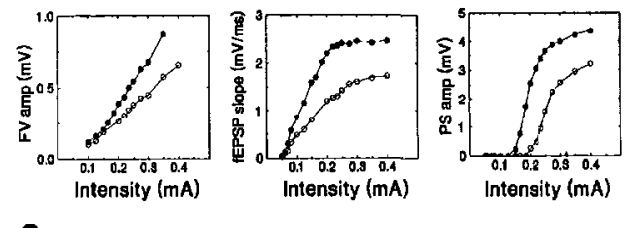

C
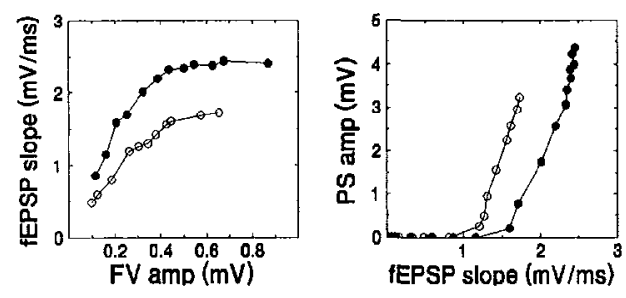

Figure 2. An increase in synaptic efficacy and FV amplitude account for the taurine-induced potentiation. $A$, The upper traces show representative averaged $(n=4)$ fEPSPs recorded at three different times $(a, b$, and $c$ on the graph) during one of the experiments used for the graph. Thin traces in $b$ and $c$ reproduce the control trace in $a$ for comparison. Arrowheads indicate the part of the evoked potential corresponding to the FV. The graph plot represents the temporal evolution of fEPSP slope (closed circles) and FV amplitude (open circles) changes induced by $10 \mathrm{~mm}$ taurine perfusion for $30 \mathrm{~min}$ in five slices. After $15 \mathrm{~min}$ of taurine withdrawal, stimulus strength was reduced (indicated by an arrow) to size-match the FV amplitude with control values. Note that although the FV amplitude was the same as in the control period, fEPSP still remain potentiated. Calibration: $0.5 \mathrm{mV}, 1 \mathrm{msec}$. $B$, Stimulus-response curves for FV amplitude, fEPSP slope, and PS amplitude, the points corresponding to single values from a representative experiment of a total of four that were also included in the graph of Figure 14 . Data recorded during the control period are depicted by open circles; closed circles represent those data obtained after $60 \mathrm{~min}$ of $10 \mathrm{~mm}$ taurine withdrawal. $C$, Data in $B$ were used to construct input-output curves. Open and closed circles have the same meaning as in $B$. On the left can be seen the leftward shift in the fEPSP/FV relation after $60 \mathrm{~min}$ of taurine washout, which indicates an increase in synaptic efficacy induced by taurine. On the contrary, the PS/EEPSP relation shifts to the right after $60 \mathrm{~min}$ of taurine washout.

\section{Taurine-induced potentiation is independent of $\mathrm{GABA}_{A}$ or NMDA receptor activation}

The early inhibitory action of taurine on fEPSP shown above could be a $\mathrm{GABA}_{\mathrm{A}}$-like action, similar to the reported shunt of synaptic currents after $\mathrm{GABA}_{\mathrm{A}}$ receptor activation by GABA (Qian and Sejnowski, 1990; Staley and Mody, 1992). However, the long-lasting enhancement of fEPSPs induced by taurine is a totally new and unexpected action of this amino acid. Thus, to confirm the first consideration and to disclose a possible contribution of $\mathrm{GABA}_{\mathrm{A}}$ receptor activation in the new taurine action, we next performed experiments in the presence of the $G A B A_{A}$ receptor antagonists BMI or picrotoxin. Because similar results were 

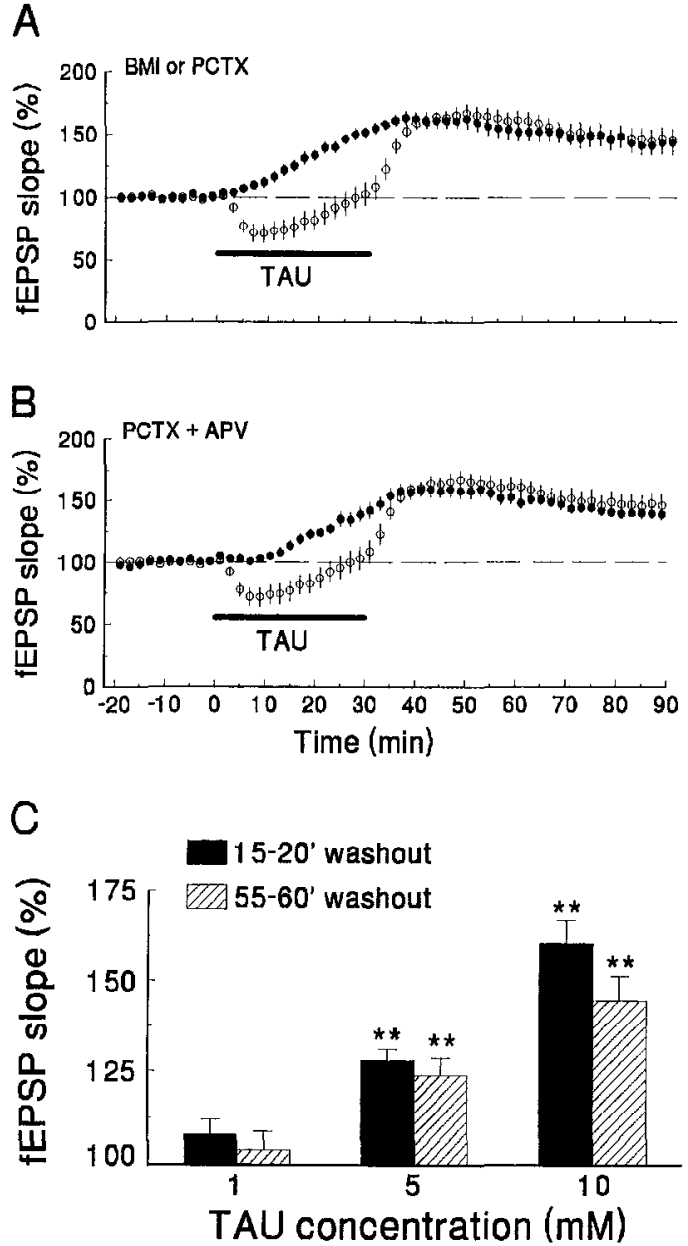

Figure 3. Taurine-induced potentiation is independent of $\mathrm{GABA}_{\mathrm{A}}$ or NMDA receptor activation. Open circles in $A$ and $B$ correspond to the experiments performed in standard medium and shown in Figure $1 A$ and are plotted here to compare with the experiments, represented by closed circles, in the presence of $50 \mu \mathrm{M}$ BMI $(n=6)$ or $100 \mu \mathrm{M}$ picrotoxin $(\mathrm{PCTX})(n=10)(A)$, or $50 \mu \mathrm{M}$ APV and $100 \mu \mathrm{M}$ picrotoxin $(n=6)(B)$. Note that the taurine-induced decrease in the fEPSP slope is totally inhibited by $\mathrm{GABA}_{\mathrm{A}}$ antagonists, but the fEPSP potentiation after taurine washout is very similar in standard medium, in the presence of $\mathrm{GABA}_{\mathrm{A}}$ antagonists and in the presence of NMDA antagonists $(p>0.05$; two-way ANOVA). $C$, In the presence of BMI or picrotoxin, taurine was perfused for 30 min at three different concentrations ( $1 \mathrm{mM}, n=5 ; 5 \mathrm{mM}, n=5 ; 10$ $\mathrm{mM}, n=16)$. The histograms represent the fEPSP potentiation level corresponding to 15-20 min (black bars) and 55-60 min (striped bars) after taurine withdrawal. Asterisks indicate significative changes $\left({ }^{* *} p<0.01\right)$ compared with control values.

obtained with the two antagonists, both sets of experiments have been pooled. Figure $3 A$ shows that when $10 \mathrm{~mm}$ taurine was perfused in the presence of $50 \mu \mathrm{M}$ BMI $(n-6)$ or $100 \mu \mathrm{M}$ picrotoxin $(n=10)$, the inhibitory action of taurine was absent and an increase in the fEPSP could be observed from the beginning of taurine perfusion. The magnitude and time course of fEPSP potentiation after taurine washout in experiments with BMI or picrotoxin $(144.3 \pm 6.8 \%, n=16$, after $1 \mathrm{hr}$ of taurine washout; $144.6 \pm 6.1 \%, n=4$, after $2 \mathrm{hr}$; and $137.5 \pm 4.3 \%, n=$ 3 , after $3 \mathrm{hr}$ ) were totally similar to those obtained in experiments performed in the absence of $\mathrm{GABA}_{\mathrm{A}}$ antagonists. Thus, GABA receptor activation is not involved in the taurine-induced fEPSP potentiation.
In the presence of $\mathrm{GABA}_{\mathrm{A}}$ receptor antagonists, we studied the dependence of IEPSP potentiation on laurine concentration. In Figure $3 C$ the level of fEPSP potentiation attained after taurine perfusion at $1(n=5), 5(n=5)$, or $10 \mathrm{~mm}(n=16)$ for a $30 \mathrm{~min}$ period is depicted. The small fEPSP potentiation induced by $1 \mathrm{mM}$ taurine perfusion was not statistically significant $(p>0.05)$.

Because NMDA receptor activation is directly implicated in some forms of synaptic potentiation in the hippocampus (Bliss and Collingridge, 1993), and because taurine is structurally similar to glycine, an amino acid that has a positive allosteric regulatory site in the NMDA receptor (Johnson and Ascher, 1987), we also studied whether taurine-induced potentiation could be mediated by NMDA receptor activation. The experiment depicted in Figure $3 B$ shows that this is not the case, because taurine perfusion in the presence of $50 \mu \mathrm{M} \mathrm{APV}$, an NMDA receptor antagonist, evoked an fEPSP potentiation indistinguishable from that of the experiments without NMDA receptor antagonists.

\section{Taurine increases EPSPs and IPSPs without changes in membrane electrical properties}

Because all of the field potentials studied herein (fEPSP, PS, and FV) increase by the action of taurine perfusion, we wondered whether these changes could be attributable to field effects affecting extracellular current flow on the recorded cell population. We could rule out this possibility if it were found that taurine also increases synaptic potentials recorded intracellularly. In addition, intracellular recordings can reveal possible changes in $V_{m}$ and $R_{\text {in: }}$. We studied this issue in a series of intracellular experiments $(n=$ 7) in which electrical stimulation was adjusted to evoke an FPSP that could increase without eliciting the action potentials to fire. The average $V_{m}$ in these cells was $-70.3 \pm 1.6 \mathrm{mV}$. Perfusion of $10 \mathrm{~mm}$ taurine for $20 \mathrm{~min}$ in the presence of BMI induced, in a similar way as in the extracellular experiments, an increase in EPSP amplitude (maximum of $49.8 \pm 15 \%$ over basal levels; $p<$ 0.01 ) that stayed potentiated, although with a downward trend until the end of taurine washout (50 min) (Fig. $4 A$ ). The $V_{m}$ and $R_{\text {in }}$ did not change significantly throughout the experiment (Fig. $4 A$ for $R_{\text {in }}, p>0.05$; one-way ANOVA). Only during taurine perfusion was there a small $V_{m}$ hyperpolarization $(1.3 \pm 0.6 \mathrm{mV})$ and a small decrease $(1.6 \pm 0.7 \mathrm{M} \Omega)$ in $R_{\text {in }}$ observed. Therefore, the increase of the EPSP induced by taurine was not accompanied by any significant change in membrane potential or input resistance, although small changes in the membrane electrical properties of the dendrites, not detected by the somatic recordings, cannot be discarded.

In another series of intracellular experiments $(n=3)$, we studied whether taurine perfusion affects monosynaptic IPSPs. Monosynaptic IPSPs (both fast and slow IPSPs) can be evoked by direct electrical stimulation of interneurons close to the recorded neuron, in the presence of non-NMDA receptor antagonist CNQX $(20 \mu \mathrm{M})$ and the NMDA receptor antagonist APV $(50 \mu \mathrm{M})$ (Davies et al., 1990). The $V_{m}$ of the cells was shifted away from the fast IPSP reversal potential by injecting positive $\mathrm{DC}$ current to reach a $V_{m}$ of $-63 \pm 1 \mathrm{mV}$. In this condition, $10 \mathrm{mM}$ taurine perfusion for $20 \mathrm{~min}$ reduced $R_{\text {in }}$ by $\sim 70 \%$, hyperpolarized the cell in $5.6 \pm 1.5 \mathrm{mV}$, and induced a complete IPSP blockade (Fig. $4 B$ ). Because we obviously did not use $\mathrm{GABA}_{\mathrm{A}}$ antagonists in these experiments, all of these effects were probably a result of GABA $A_{\mathrm{A}}$ receptor activation by taurine. After taurine washout, $R_{\mathrm{in}}$ and $V_{m}$ recovered quickly to pretaurine values, whereas fast IPSP amplitude increased $35.3+9.5 \%$ over control values $(p<0.05)$ and remained enhanced at least $40 \mathrm{~min}$ after taurine washout. 
Figure 4. Taurine increases EPSPs and IPSPs without changes in $R_{\text {in }}$. A, Time course of $10 \mathrm{~mm}$ taurine effect on EPSP amplitude (closed circles) and $R_{\text {in }}$ (open circles) in the presence of $50 \mu \mathrm{M}$ BMI. Both EPSPs and $R_{\text {in }}$ were recorded in the same cells in different slices $(n=7)$. Traces correspond to four averaged responses taken at the times indicated by the letters on the graph in one representative cell $\left(V_{m}=-70 \mathrm{mV}\right)$. Calibration: $4 \mathrm{mV}, 40 \mathrm{msec} . B$, Time course of 10 mM taurine effect on the monosynaptic fast IPSP amplitude (closed circles) and $R_{\text {in }}$ (open circles) in the presence of $20 \mu \mathrm{M} C N Q X$ and $50 \mu \mathrm{M}$ APV. Summary data correspond to three cells recorded in different slices. Averaged $(n=5)$ potentials belong to a representative cell $\left(V_{m}=\right.$ $-62 \mathrm{mV}$ ), taken at the times indicated by the letters on the graph. Calibration: $4 \mathrm{mV}, 150$ msec. Constant hyperpolarizing current pulses were applied after the EPSP or before the IPSP to monitor $R_{\text {in }}$ throughout the experiments. Thin traces in $b$ and $c$ reproduce the trace in $a$ for comparison.

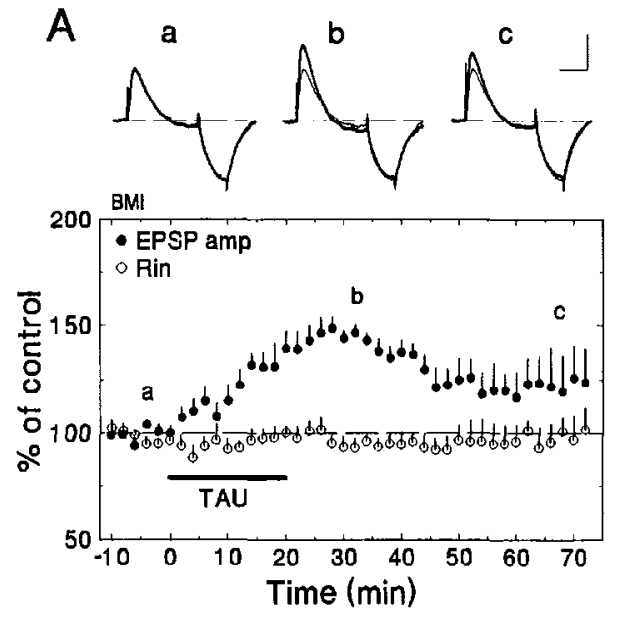

Similar results were obtained from four cells recorded with micropipettes filled with $3 \mathrm{M} \mathrm{KCl}$, in which the monosynaptic IPSPs, depolarizations in this situation, were potentiated to $160.6 \pm$ $17.3 \%$ of control values at $20-25$ min of taurine washout. Slow IPSPs also increased after taurine perfusion, but they were not studied systematically, because they were not always easily distinguishable from the last part of thc fast IPSP. This incrcasc in the magnitude of inhibitory synaptic transmission at the soma level could explain why after taurine perfusion a larger EPSP is needed to generate an action potential, as revealed by the shift to the right in PS/fEPSP curve (Fig. $2 B$, left).

\section{Taurine-induced potentiation does not change the paired-pulse facilitation ratio}

Taking into account the experiments described above, taurineinduced potentiation of synaptic potentials, both EPSPs and IPSPs, does not seem to be explained easily by a change in the basic electrical properties of postsynaptic cell membrane. Consequently, we next attempted to study whether taurine-induced EPSP potentiation involves a presynaptic mechanism that could be detected with the paradigm of paired-pulse facilitation. This stimulation pattern, which has been used to ascribe the site for induction and expression of mossy fiber long-term potentiation to the presynaptic terminals (Zalutsky and Nicoll, 1990), induces for a short time an increase in transmitter release resulting from the residual presynaptic free $\mathrm{Ca}^{2}$ levels (Hess and Kuhnt, 1992). In Figure 5 it is shown that taurine potentiates the first and second potentials, elicited by a pair of stimuli separated by a $50 \mathrm{msec}$ interval, proportionally; therefore, the normalized facilitation ratio (second pulse/first pulse) did not change either during taurine perfusion or during taurine washout ( $p>0.05$; one-way ANOVA). Thus, taurineinduced potentiation does not seem to interfere with the presynaptic mechanism involved in paired-pulse facilitation.

\section{Taurine increases the amplitude of pharmacologically isolated FV}

As pointed out in the first section of results, taurine-induced fEPSP potentiation is partially a result of the FV increase. Other authors (Buckle and Haas, 1982; Lærum and Storm, 1994) have shown that synaptic potentiation evoked by $\mathrm{K}^{+}$channel blockers is accompanied by presynaptic spike broadening. We have isolated pharmacologically the FV from the fEPSP to study better how the changes are induced by taurine in this presynaptic potential, and also to compare these changes with those evoked by 4-AP, a $\mathrm{K}^{+}$channel blocker. In three experiments, we completely blocked fEPSP generation by perfusing the slices with a medium containing $20 \mu \mathrm{M} \mathrm{CNQX}$ and $50 \mu \mathrm{M} \mathrm{APV}$, and the isolated FV remained unaltered (Fig. 6A). After a baseline period of $20 \mathrm{~min}$, taurinc $(10 \mathrm{mM})$ perfusion for $30 \mathrm{~min}$ induced, as in the experiments represented in Figure 1A, a progressive enhancement of the FV amplitude. This increase was $67.9 \pm 5.5 \%(n=3)$ over
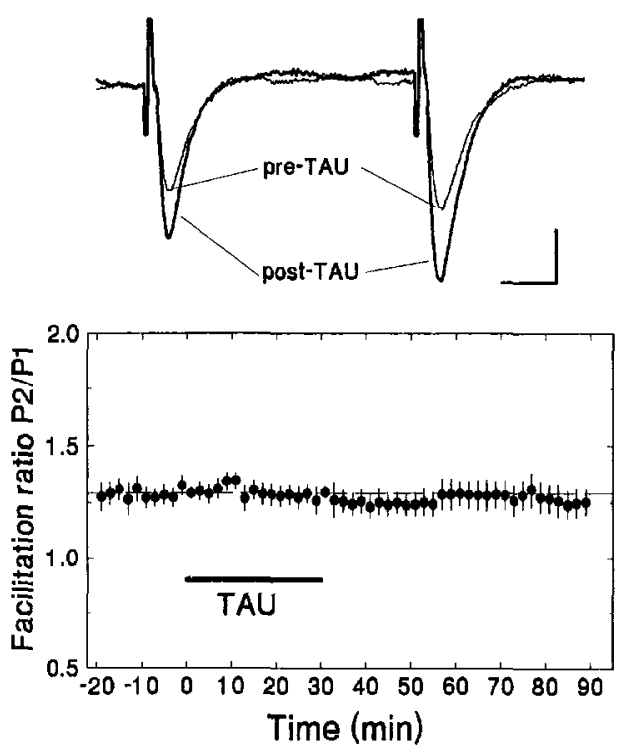

Figure 5. Paired-pulse facilitation ratio is not modified by the taurineinduced potentiation. Superimposed averaged $(n=4)$ recordings of fEPSP pairs evoked by two stimuli separated by $50 \mathrm{msec}$ are from one of the experiments summarized in the graph. Thin and thick traces correspond to pre- and post-taurine application, as indicated, and show that the fEPSP remains potentiated after $30 \mathrm{~min}$ of taurine withdrawal. The level of potentiation obtained after 15-20 min of taurine washout in the six experiments was $60.4 \pm 13.4 \%$ for the first pulse and $58.1 \pm 9.7 \%$ for the second pulse. The plot summarizes the time course of paired-pulse facilitation ratio (second fEPSP slope/first fEPSP slope) continuously monitored during six experiments, performed in $50 \mu \mathrm{M}$ BMI or $100 \mu \mathrm{M}$ picrotoxin, in which $10 \mathrm{~mm}$ taurine was perfused. The facilitation ratio does not change during taurine perfusion or the taurine washout period ( $p$ $>0.05$; one-way ANOVA). Calibration: $0.5 \mathrm{mV}, 10 \mathrm{msec}$. 
A
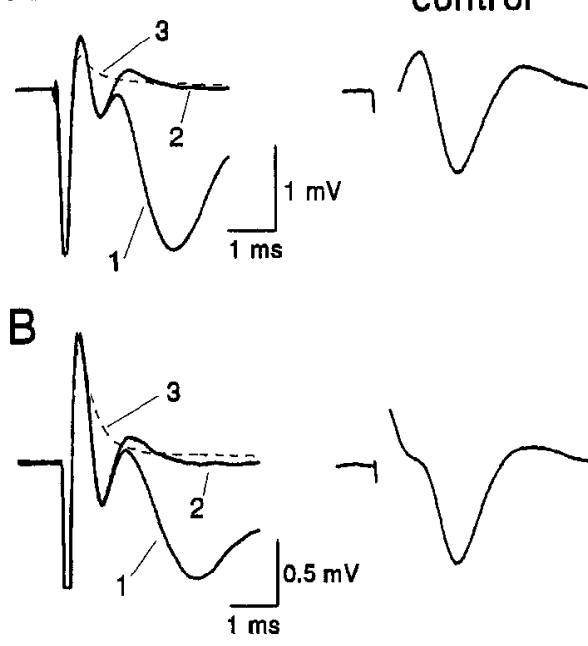

TAU
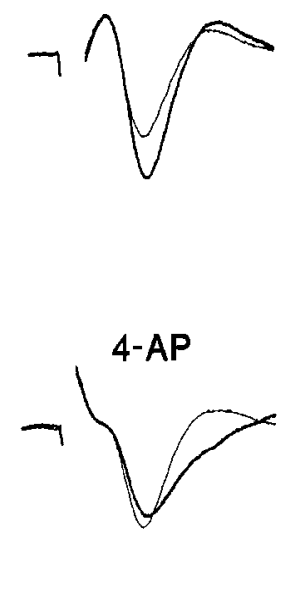

normalized
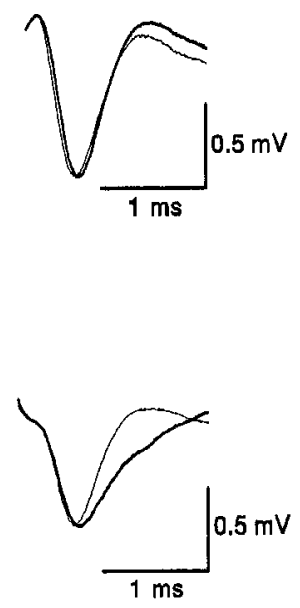

Figure 6. Taurine increases the FV amplitude, whereas 4-AP enhances FV repolarization timc. $A$, Recordings are averages $(n=4)$ from an experiment in which perfusion medium was changed as follows. After $5 \mathrm{~min}$ in standard medium, a medium with $20 \mu \mathrm{M}$ CNQX and 50 $\mu \mathrm{M}$ APV was perfused through the experiment. Twenty minutes later, $10 \mathrm{~mm}$ taurine was added for $30 \mathrm{~min}$ and, thereafter, taurine washout was done for $30 \mathrm{~min}$. At the end of the experiment, $1 \mu \mathrm{M}$ TTX was perfused to verify that the potential remaining after CNQX and APV was an FV. The first traces on the left show superposition of three averages showing (1) the FV and fEPSP recorded in the standard medium; (2) the FV isolated after blocking the fEPSP with CNQX and APV; and (3) the stimulus artifact (dotted line) evidenced after the addition of TTX. This artifact was subtracted to yield the theoretically pure FV shown in the right columns. Enlarged isolated FVs shown on the other columns were obtained: in CNQX and APV (control), after $30 \mathrm{~min}$ of taurine washout $(T A U)$, and when the control trace was normalized to the peak amplitude of the TAU trace. Thin traces reproduce the control trace for comparison. $B$, The experimental design and record explanations are as in $A$, except that $500 \mu \mathrm{M}$ 4-AP was perfused instead of taurine. basal levels at the end of taurine perfusion time, and stayed potentiated for $1 \mathrm{hr}$ of taurine washout period. At the end of the experiment, $1 \mu \mathrm{M}$ TTX was perfused to confirm which part of the potential corresponds to FV and which part results from the stimulus artifact. The remaining potential in TTX was subtracted from the potential in CNQX and APV to obtain a theorctically pure FV. In this condition, as depicted in Figure $6 A$, taurine induces an increase in FV amplitude but does not affect the kinetics of the FV, as revealed by scaling control potential to the amplitude of the potentiated FV. In another three slices we performed similar experiments, but perfusing 4-AP $(500 \mu \mathrm{M})$ instead of taurine. In this case we obtained a broadening of the FV, as reported previously by Lærum and Storm (1994). In contrast, we observed a small reduction of both amplitude and initial slope of the FV, probably indicating that, in addition to the effect of 4-AP on the presynaptic action potential repolarization, there is also a desynchronization of the action potential firing in different fibers. These experiments clearly point out that taurineinduced potentiation of the $\mathrm{FV}$ is not compatible with a taurine action on those presynaptic $\mathrm{K}^{+}$channels contributing to spike repolarization.

\section{Taurine reduces fiber firing threshold}

One suitable explanation for a taurine-dependent increase in the FV amplitude is that a larger number of fibers fire synchronously in response to a determined stimulus. If taurine perfusion is increasing the FV amplitude by this mechanism, it has to be assumed that taurine is facilitating the firing of individual fibers. In a group of intracellular experiments, we have addressed this issue by monitoring the threshold for eliciting antidromic action potential in CA3 (stimulating Schaffer collaterals) or in CA1 pyramidal neurons (stimulating in stratum alveus). The experiments were performed in the presence of CNQX, APV, and picrotoxin (in these experiments anatomical connections between $\mathrm{CA} 1$ and $\mathrm{CA} 3$ were preserved, and the concentrations of $\mathrm{Ca}^{2+}$ and $\mathrm{Mg}^{2+}$ were as in standard medium). The antidromic action potential threshold was obtained by electrical stimulation pulses at an intensity between 50 and $130 \mu \mathrm{A}$ and between 100 and $180 \mu \mathrm{sec}$ duration. After the threshold was initially assessed, its actual value throughout the experiment was monitored by changing stimulus duration in 5 $\mu$ sec steps in such a way that, if the stimulus induced an antidromic response, then the duration of the next stimulus was decreased in $5 \mu \mathrm{sec}$. If not, the stimulus duration was increased in an identical amount. In Figure $7 A$ the data corresponding to one of these experiments are shown. Closed and open circles represent those stimuli eliciting or not eliciting antidromic action potentials, respectively. After a baseline period of at least $15 \mathrm{~min}, 10 \mathrm{~mm}$ taurine perfusion for $20 \mathrm{~min}$ induced a progressive decrease in the stimulus duration needed to evoke antidromic action potentials. This threshold remained decreased after a minimum of $1 \mathrm{hr}$ of taurine washoul. The antidromic action potential shape apparently did not change during taurine perfusion or washout, as can be seen in the inset in Figure $7 A$, in which each trace corresponds to a record obtained every $10 \mathrm{~min}$ of the experiment. The decrease in the antidromic action potential threshold induced by taurine is of the same order in CA1 cells $(n=3)$ as in CA3 cells $(n=3)$; thus, we have pooled together the results from both types of cells (Fig. $7 B$ ). In these averaged data, in which each stimulus duration value was laken into account independent of its ability to elicit action potential, it can be observed that taurine induced a progressive stimulus threshold decrease, which attained a maximal reduction of $44.3 \pm 6.5 \%(n=6)$ at $15-20$ min after taurine withdrawal. Because the temporal sequence of changes described here for the antidromic action potential threshold is quite similar to the temporal sequence of increase induced by taurine in both FV (Fig. $1 A$ ) and EPSP (Figs. $3 A, B$, $4 A$ ), it is plausible that changes in the presynaptic fiber activation are one of the primary causes of taurine-induced potentiation of synaptic potentials.

In view of these results we reasoned that if taurine changes the axon firing threshold, it could also affect the threshold of action 
A
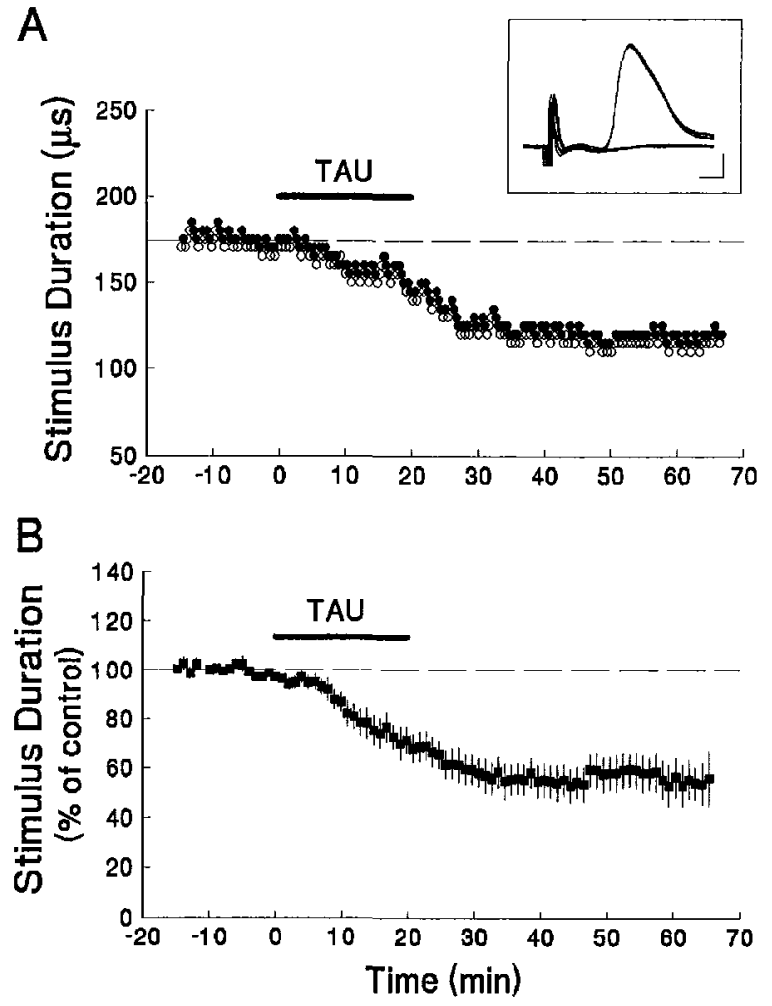

Figure 7. Taurine induces a long-lasting decrease in the stimulus threshold to evoke antidromic action potential in CA1 and CA3 cells. $A$, A particular experiment performed in the presence of $20 \mu \mathrm{M} C \mathrm{NQX}, 50$ $\mu \mathrm{M}$ APV, and $100 \mu \mathrm{m}$ picrotoxin. After determining a stimulus of optimal intensity and duration, the stimulus threshold was tracked throughout the experiment. This was achieved by increasing or decreasing the stimulus duration (in $5 \mu \mathrm{sec}$ ) if the previous stimulus had failed (open circles) or succeeded (closed circles), respectively, to generate an antidromic action potential. Inset recordings show the superposition of eight antidromic action potentials evoked in CA1 by stimulation in the stratum alveus, and that they were chosen every $10 \mathrm{~min}$ from the beginning to the end of the experiment. Also, eight stimuli that did not evoke action potentials are depicted. Recordings are synchronized with the action potential initial phase. The jilter in the stimulus artifact is atlribulable to changes in the stimulus duration. No consistent appreciable changes in spike amplitude and width were detected during the experiment. Calibration: $20 \mathrm{mV}, 0.5$ msec. $B$, Stimulus threshold (average of six cells: three from CAl and three from $\mathrm{CA} 3$ ) decreases by taurine effect, indicating a long duration in axon excitability. All of the stimulus duration values, regardless of whether they were able to elicit action potential, were used to average the graph. Stimulus duration was decreased to $55.7 \pm 6.4 \%$ of control values after $15-20$ min of taurine washout $(p<0.01)$ and to $54.6+8.1 \%$ of control values after $40-45 \mathrm{~min}$ of taurine washout $(p<0.01)$.

potential activation at the somatic level. We addressed this issue in six CA1 cells in the presence of $100 \mu \mathrm{M}$ picrotoxin. Action potential firings were evoked by applying, through the recording pipette, depolarizing current ramps (from 0 to $300 \mathrm{pA}$ in $13 \mathrm{msec}$ ) every $20 \mathrm{sec}$ throughout the experiment. The mean firing level of the six cells recorded was $-55.52 \pm 1.01 \mathrm{mV}$ during the control period, $-57.09 \pm 1.53 \mathrm{mV}$ during the last $5 \mathrm{~min}$ of a $20 \mathrm{~min}$ taurine $(10 \mathrm{mM})$ perfusion period, and $-56.10 \pm 2.09 \mathrm{mV}$ during the last $5 \mathrm{~min}$ of a $30 \mathrm{~min}$ taurine washout period. Statistical differences among these means were not significant $(p>0.05)$, indicating that taurine does not change pyramidal cell firing threshold during either its perfusion or its washout. There are no obvious explanations to interpret this apparently specific action of taurine on firing threshold, which occurs in axons but not in somas, and considering the present state of research on this subject, any interpretation would be very speculative. The existence of different $\mathrm{Na}^{+}$channel subtypes segregated to axons and cell bodies (for review, see Catterall, 1992) could bring some hints to explain taurine action on axon excitability.

\section{Taurine has to be taken up to induce synaptic potentiation}

The narrow range of pharmacological tools for examining taurine prevents a physiological assessment of these results. Several authors (Franconi et al., 1982; Sebring and Huxtable, 1985; Lake et al., 1987) have proposed an intracellular locus for the taurine ionotropic action on heart tissue. Because a specific extracellular receptor for taurine has not yet been found, we wonder whether it is necessary to perfuse high concentrations of taurine because an intracellular compartment has to be filled with this amino acid to induce synaptic potentiation. In this context we have to recall a fact that is inherent to the slice preparation: during the slicing procedure and the subsequent slice recovery time and perfusion, a large fraction $(\sim 70 \%)$ of the total endogenous content of taurine is lost (Hamberger et al., 1982) (M. Galarreta, J. Bustamante, R. Martín del Río, and J. M. Solís, unpublished observations). When the taurine content was analyzed in some slices in which $10 \mathrm{~mm}$ taurine was perfused for $30 \mathrm{~min}$, it was observed that after $1 \mathrm{hr}$ of taurine withdrawal, the concentration of this amino acid in the slice was nearly 5 times higher than those measured in the slices not perfused with taurine (M. Galarreta, J. Bustamante, R. Martín del Río, and J. M. Solís, unpublished observations). Then we can envisage the effects of taurine perfusion on synaptic potentials as the result of intracellular taurine level restitution. If this assumption were correct, the time course of taurine action could be rate-limited by a taurine uptake system.

Following the above reasoning, we implemented some experimental strategies to disclose whether transport systems are involved in the taurine-induced fEPSP potentiation. Taurine uptake, as in the case of other amino acid transport systems, is highly sensitive to temperature and sodium gradient (Hruska et al., 1978; Kontro and Oja, 1981; Liu et al., 1992). Thus, we made experiments at $20-21$ instead of $31-32^{\circ} \mathrm{C}$, which is the temperature normally used in our experiments. At low temperature, $10 \mathrm{~mm}$ taurine in a standard medium induced a small and stable fEPSP depression throughout the $30 \mathrm{~min}$ perfusion period (Fig. 8A). After taurine washout, fEPSP increased significantly less, $112.6 \pm$ 5.6 and $106.1 \pm 8.7 \%(n=6)$ at $15-20$ and 55-60 min taurine washout, respectively, than when experiments were made at 31$32^{\circ} \mathrm{C}: 165.2 \pm 6.8$ and $146.5 \pm 8.4 \%(n=15)$ at $15-20$ and $55-60$ min taurine washout, respectively $(p<0.01)$.

Sodium dependence of taurine-induced potentiation was assessed in experiments in which all $\mathrm{NaCl}$ in the perfusion solution was equimolarly replaced by $N$-methyl-D-glucamine chloride (Fig. $8 B$ ). In this condition all of the evoked potentials rapidly disappeared. We first tested how the reintroduction of control $\mathrm{Na}^{+}$ concentration after $1 \mathrm{hr}$ of low $\mathrm{Na}^{+}$perfusion could affect, by itself, the synaptic potentials. After $\mathrm{Na}^{+}$reposition there was a rebound in the fEPSP slope that stayed enhanced after $1 \mathrm{hr}$ of control perfusion with standard medium (134 \pm 15.8 and $122.2 \pm$ $9.8 \%$ after $15-20$ and 55-60 min of $\mathrm{Na}^{+}$reintroduction, respectively, $n=4$ ). In other experiments, after 25 min of low $\mathrm{Na}^{+}$ perfusion, $10 \mathrm{~mm}$ taurine was perfused for $30 \mathrm{~min}$ in low $\mathrm{Na}^{+}$. After 5 min of taurine washout, $\mathrm{Na}^{+}$ions were restored and the fEPSP rapidly increased over control values and remained potentiated for $1 \mathrm{hr}$. Subtracting the fEPSP enhancement attributable to low $\mathrm{Na}^{+}$perfusion per se from the increase detected after 

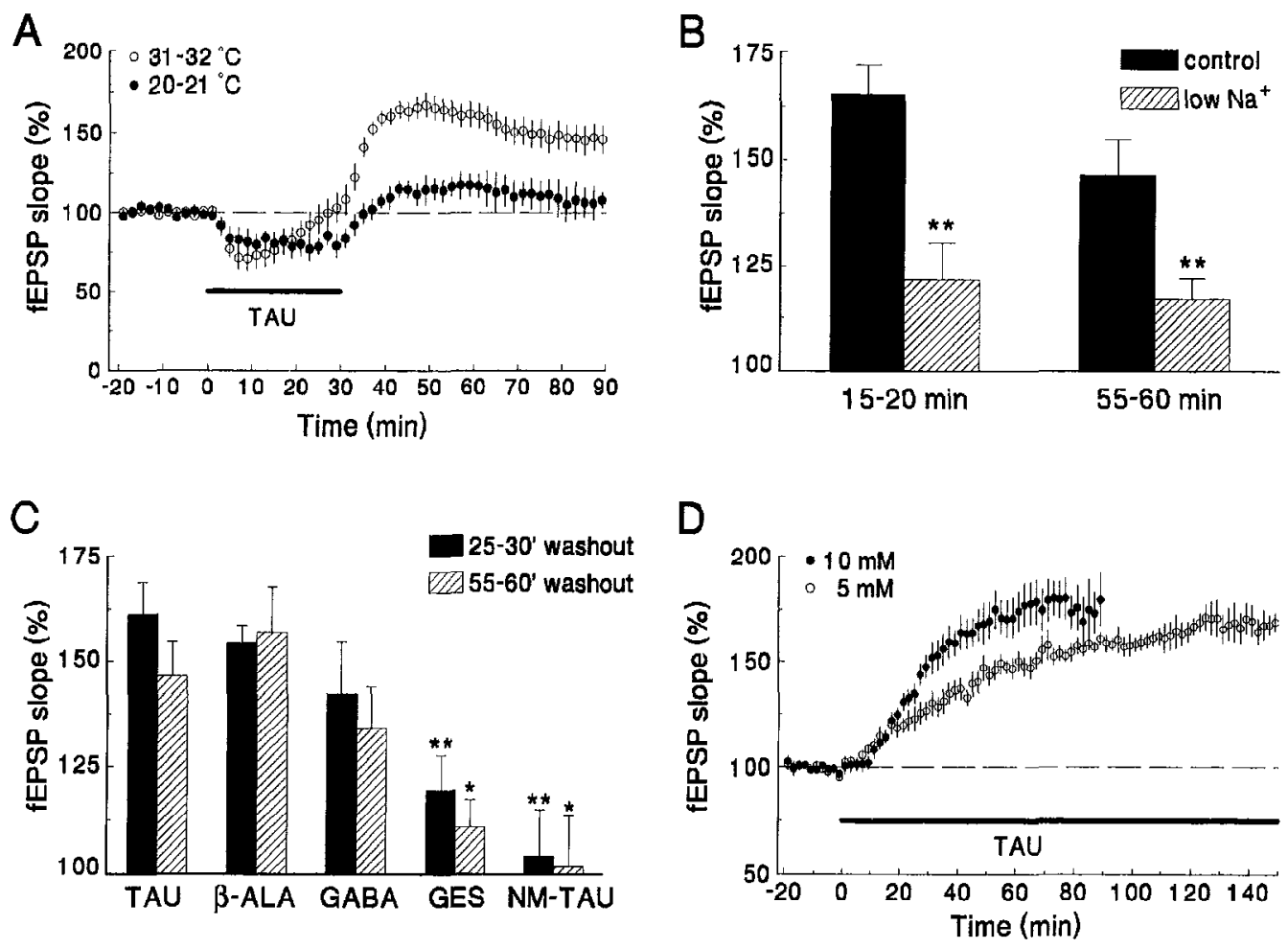

Figure 8. Taurine uptake is needed to induce fEPSP potentiation, $A$, Temperature dependence of taurine-induced potentiation. Open circles correspond to the experiments performed in standard medium at $31-32^{\circ} \mathrm{C}$ that were shown in Figure $1 A$ and are plotted here to compare with the experiments $(n=6)$ represented by closed circles at $20-21^{\circ} \mathrm{C}$. Taurine-induced potentiation is significantly smaller at low temperatures than at $31-32^{\circ} \mathrm{C}$ (potentiation after $15 \mathrm{~min}$ of taurine withdrawal, $p<0.01$; two-way ANOVA). $B$, Sodium dependence of taurine-induced potentiation. All of the $\mathrm{NaCl}$ content in the standard medium was equimolarly replaced by $N$-methyl-D-glucamine chloride. Data $(n=5)$ depicted as striped bars in the histogram were obtained at 15-20 and 55-60 min of taurine washout after subtracting the fEPSP enhancement attributable to low Na ${ }^{+}$ perfusion per se from the increase detected after taurine washout and $\mathrm{Na}^{+}$restoration. Black bars in the histogram show fEPSP potentiation values at 15-20 and 55-60 min of taurine washout from the 15 experiments shown in Figure $1 \mathrm{~A}$. Taurine-induced potentiation is smaller in low Na ${ }^{+}$than in standard $\mathrm{Na}^{+}\left({ }^{*} p<0,01\right)$. C, Several taurine analogs that are substrates of the taurine uptake systen also induce fEPSP potentiation. All of the substances were perfused at a final concentration of $10 \mathrm{~mm}$ for $30 \mathrm{~min}$. Black and striped bars represent fEPSP potentiation values after $25-30$ and 55-60 min of taurine washout, respectively. Four experiments were made for each substance tested, except for taurine $(n=15)$, the values of which correspond to data used in Figure $1 A$. Statistical significance of the comparisons between potentiations induced by taurine analogs against taurine are expressed as follows: ${ }^{*} p<0.05 ;{ }^{* *} p<0.01$. D, Taurine at a concentration of $5 \mathrm{~mm}$ (open circles, $\left.n=4\right)$ or $10 \mathrm{~mm}($ closed circles, $n=$ 5 ) was perfused continuously until a saturation of fEPSP potentiation was attained. These experiments were performed in the presence of $100 \mu \mathrm{M}$ picrotoxin.

taurine washout and $\mathrm{Na}^{+}$restoration, the fEPSP potentiation induced by taurine is obtained (Fig. $8 B$ ). This potentiation is smaller than that obtained with a normal $\mathrm{Na}^{+}$concentration $(121.7 \pm 8.7$ and $117.1 \pm 5.5 \%, n=5$, at $15-20$ and $55-60 \mathrm{~min}$, respectively, in low $\mathrm{Na}^{+}$vs $165.2 \pm 6.8$ and $146.5 \pm 8.4 \%, n=15$, at 15-20 and 55-60 min, respectively, in normal $\mathrm{Na}^{+}, p<0.01$ ).

We further tested the hypothesis, wherein taurine must be taken up as a previous step to induce fEPSP potentiation, by examining the effects of several structurally related taurine analogs such as $\beta$-alanine, GABA, GES, and NM-TAU on the fEPSP. Both $\beta$-alanine and GABA share the same transport system with taurine (Martin and Shain, 1979; Holopainen et al., 1983), so they would be expected to mimic taurine-induced potentiation. GES is a low-affinity substrate of the taurine uptake system that acts as a competitive inhibitor (Huxtable et al., 1979; Holopainen et al,, 1987), and NM-TAU is not a good substrate of taurine carrier (Kontro and Oja, 1983); therefore, these two substances were not expected to induce fEPSP potentiation. $\beta$-Alanine, GABA, GES, or NM-TAU were perfused at a concentration of $10 \mathrm{mM}$ for 30 min with the aim of comparing their possible action on the fEPSP with the cffect described above for taurine. During $\beta$-alaninc perfusion, fEPSP diminished by $>70 \%$, and increased after its washout, as in the case of taurine, remaining enhanced to $157.1 \pm$ $10.7 \%(n=4)$ of basal levels after 55-60 min of the washout period. During GABA perfusion, fEPSPs were completely abolished and recovered in a few minutes after GABA washout. The potentiating effect of GABA on the fEPSP was somewhat smaller $(134.1 \pm 9.8 \%$ at $55-60 \mathrm{~min}$ of washout, $n=4)$ than that reported for taurine and $\beta$-alanine (Fig. $8 C$ ). The action of $\operatorname{GES}(n=4)$ was much less important in potentiating the fEPSP $(110.8 \pm 6.6 \%$ at 55-60 min of washout), although the fEPSP depression was quite similar to that induced by taurine $(61.2 \pm 5.5 \%$ after $10 \mathrm{~min}$ of GES perfusion). NM-TAU $(n=4)$ did not modify the fEPSP during its perfusion or during the washoul period.

If taurine is potentiating synaptic transmission by acting on an intracellular locus, then if one allows enough taurine perfusion time with different taurine concentrations (5 and $10 \mathrm{~mm}$ ) the fEPSP would reach the same level of potentiation in all cases, but with a different rate of increase. With this idea, experiments with different taurine concentrations were performed in the presence of $100 \mu \mathrm{M}$ picrotoxin until the fEPSP potentiation attained a saturation level. Figure $8 D$ shows the time course of fEPSP increase with taurinc concentrations of 5 or $10 \mathrm{~mm}$. It can be scen that although the rate of fEPSP increase is faster with the higher 
concentration of taurine (the half-maximal increase is $39.5 \mathrm{~min}$ for $5 \mathrm{~mm}$ and $25.5 \mathrm{~min}$ for $10 \mathrm{~mm}$ ), the maximal fEPSP increment attained with the two taurine concentrations is, however, quite similar $(168.7 \pm 5.9 \%(n=4)$ for $5 \mathrm{mM}$, and $171.8 \pm 7.2 \%(n=$ 5) for $10 \mathrm{~mm} ; p>0.05)$. It should be noted that although the fEPSP increase with $10 \mathrm{~mm}$ taurine is faster, its beginning is delayed in comparison with the lower concentration. This could be a result of the fact that such a high concentration of taurine may overcome partially the picrotoxin effect on $\mathrm{GABA}_{\mathrm{A}}$ receptors and, thus, during the first minute of $10 \mathrm{~mm}$ taurine perfusion, a balance between the inhibitory action of taurine and the potentiation effect could exist. The experiments described in this paragraph indicate that the magnitude at which taurine-induced potentiation saturates, at least in the range of taurine concentration used here, is dependent on the taurine perfusion time rather than on the taurine concentration, this last parameter being related with the rate of fEPSP increase.

Nevertheless, taking all of these groups of results together it could be suggested that taurine uptake is required for taurineinduced potentiation. We must call attention to the fact that these observations are indirect evidence to support this suggestion. This is because the possibility of nonspecific effects, evoked by low temperature or low $\mathrm{Na}^{+}$, on those cell functions related to the ultimate mechanism responsible for the taurine-induced potentiation cannot be ruled out. In fact, it has been shown that another form of synaptic potentiation, such as long-term potentiation in CA1, may be reversed by brief cooling $\left(24^{\circ} \mathrm{C}\right)$ shocks of bath temperature (Bittar and Muller, 1993).

\section{DISCUSSION}

In these experiments on the effect of taurine perfusion on excitatory synaptic potentials, we mainly have found two actions: (1) a reversible reduction in EPSP slope, which is compatible with the well known shunt of EPSP currents by $\mathrm{GABA}_{\mathrm{A}}$ receptor activation; and (2) a long-lasting increase of the EPSP slope, the time course of which is fully observed in the presence of GABA $_{A}$ receptor antagonists. The latter is a new electrophysiological action of taurine that deserves experimental characterization from the very beginning.

The magnitude and duration of the taurine-induced increase of the fEPSP are dependent on the taurine perfusion time (Fig. $1 B$ ). These experiments also suggest that there exists a taurine perfusion time threshold for the maintenance of the longlasting increase in fEPSP. The permanence of high amounts of taurine during the washout period is not a plausible explanation for the EPSP potentiation maintenance, because the $\mathrm{GABA}_{\mathrm{A}}$-like actions of taurine reversed in a few minutes (Figs. $1 A, 5 B)$, whereas taurine-induced potentiation lasted at least 3 hr. Moreover, perfusion with $1 \mathrm{mM}$ taurine solution for $30 \mathrm{~min}$ did not evoke significant changes in the EPSP (Fig. $3 C$ ).

Taurine-induced synaptic potentiation consists of two longlasting factors: (1) the increase in the synaptic efficacy detected by the shift to the left in the fEPSP/FV curves; and (2) the enhancement of axon excitability detected by the increase of FV amplitude. A long-lasting increase in the presynaptic FV amplitude has not been reported to be involved in the EPSP potentiation evoked by several substances (Bliss and Collingridge, 1993). Recently, however, Chinestra et al. (1994) reported that the slow onset potentiation induced by a sclcctive metabotropic glutamatc receptor agonist is explained by the increase in FV amplitude without changes in the synaptic efficacy. Moreover, this FV potentiation was not induced when anatomical connections between
CA1 and CA3 subfields were severed, which is a differential factor with the taurine-induced synaptic potentiation, because in that situation taurine was able to induce both the increase in synaptic efficacy and the enhancement in the FV amplitude. A permanent change in the basic electrical properties of the postsynaptic cell does not appear to be the cause of the shift in the fEPSP/FV curve, because in the intracellular recordings, in the presence of $\mathrm{GABA}_{\mathrm{A}}$ antagonists, no significant changes in $V_{m}$ or $R_{\mathrm{in}}$ were observed during either taurine perfusion or washout. Neither does a deinhibition seem to be a plausible explanation for the increase in synaptic efficacy according to the cnhancement of inhibitory synaptic potentials caused by taurine. We have also tested a possible presynaptic contribution on the taurine-induced potentiation by using the paired-pulse facilitation paradigm. Taurine did not change the facilitation ratio, which suggests that the potentiation induced by this amino acid does not interfere with the presynaptic mechanisms involved in this kind of facilitation. With the experiments reported here, we cannot assess with certainty where taurine is acting to induce the increase in synaptic efficacy. The presence of taurine in synaptic terminals engaged in asymmetric contacts with spines in CA1 pyramidal cells (Torp et al., 1992) could be an indication that this amino acid somehow is involved in the excitatory terminals' function.

On the other hand, the potentiation factor attributable to the long-lasting increase in the $\mathrm{FV}$ amplitude is a clear indication that taurine is affecting presynaptic Schaffer collateral fibers. We have found that taurine induces a long-lasting increase in FV amplitude without changes in the repolarization time, whereas 4-AP evokes a reversible small decrease in amplitude and a broadening of FV. This broadening induced by 4-AP, as pointed out by other authors (Buckle and Haas, 1982; Lærum and Storm, 1994), is congruent with a delay of the action potential repolarization in individual fibers resulting from $\mathrm{K}^{+}$channel blockade. Taurine does not appear to affect those $\mathrm{K}^{+}$channels because it does not cause FV broadening (Fig. 6A). One explanation for the enhancement in the FV amplitude induced by taurine is that the firing of individual spikes occurs in a more synchronized way. We can rule out this possibility, because when FV amplitudes before and after taurine are scaled, the rise time and the time course of decay of both potentials are practically the same (Fig. $6 A$ ). The possibility of an increase in the electrical stimulation effectiveness because of local resistance changes caused by taurine-induced tissue swelling is unlikely, because the FV amplitude recorded in CA1 is not affected by osmotic shifts (Ballyk et al., 1991). Another possibility is that changes in FV amplitude could be explained by an increase in the number of individual presynaptic fibers responding to the electrical stimulation. This hypothesis is supported by the experiments showing a reduction in the threshold of antidromic action potential activation (Fig. 7). These data are consistent with the idea that a permanent increase in the excitability of Schaffer collateral axons is one of the causes of taurine-induced synaptic potentiation.

Why are such high amounts of taurine and long perfusion times required to induce EPSP potentiation? Taurine is under the action of uptake systems located in both neuronal and glial elements that remove taurine from the extracellular space. Thus, the effective taurine concentration in the extracellular space would be well below the nominal taurine concentration in the perfusion liquid. Even so, the taurine concentration used in this study should have been high enough to activate a postulated taurine receptor, provided that its affinity constant was similar to other neurotransmitter amino acids estimated in the micromolar range. 
In fact, although the concentration of taurine used in our study is well above the physiological level (between 8 and $20 \mu \mathrm{M}$ ) of this amino acid in the extracellular space (Jacobson et al., 1985; Lerma et al., 1986), it is in the cstimated range ( $-8 \mathrm{~mm})$ of concentrations of the intracellular compartment (Palkovits et al., 1986). We have shown (Fig. 8D) that long perfusion with different taurine concentrations induces the same amount of EPSP potentiation, but with a different rate of increase. Moreover, when bath temperature or extracellular $\mathrm{Na}^{+}$concentration was reduced to conditions that impair the amino acid uptake, a larger extracellular taurine concentration was expected to occur, which should have allowed higher and longer potentiations of this amino acid to be induced. However, those experimental conditions caused a smaller taurine-induced potentiation (Fig. $8 A, B$ ). Thus, this taurine behavior is not compatible with what would be expected for an effect mediated through the activation of an extracellular receptor. Instead, the time course of taurine-induced potentiation would be explained better if one considers the existence of an intracellular locus for taurine action. However, nonspecific effects of low bath temperature and low $\mathrm{Na}^{+}$(without considering their actions on taurine transport) on the mechanism ultimately responsible for the taurine-induced potentiation cannot be discarded.

Although the degree of potentiation induced by the taurine analogs used in this work ( $\beta$-alanine $\sim$ taurine $>$ GABA $>$ GES $>$ NM-TAU) is quite similar to the sequence of competition of these substances with taurine by taurine transporters (Kontro and Oja, 1981,1983 ), these data must be taken with care because, so far, only a taurine transporter that also transports $\beta$-alanine, but not GABA, has been cloned in nerve tissue (Liu et al., 1992). However, it is probable that other taurine transporters with different selectivity for taurine analogs could exist, as is the case for GABA transporters (Clark et al., 1992). Furthermore, we do not know exactly how the selectivity of taurine analogs would be for the proposed internal locus for taurine action.

Taurine is normally present in different types of axons such as Purkinje cell axons (Walberg et al., 1990), the Schaffer collateral/ commissural fiber system (Ottersen et al., 1985), and axons of the olfactory nerve layer (Didier et al., 1994). The presence of taurine in axons is congruent with the localization of a recently cloned taurine transporter in Purkinje cell axons, corpus callosum, and anterior commisure (Liu et al., 1992). Then the existence of intracellular taurine and taurine transporter in axons gives physiological support to the FV potentiation induced by taurine. How then could intracellular taurine change the presynaptic axon excitability? $\Lambda$ change in the properties of $\mathrm{Na}^{+}$channels induced by taurine could be a consequence of this amino acid, and this action would explain the increase in the FV amplitude and the decrease in the action potential firing threshold. Consistent with this idea, Satoh (1994) has shown that $20 \mathrm{~mm}$ taurine, applied internally in ventricular myocytes via a patch pipette, enhanced peak $\mathrm{Na}^{+}$current.

We have shown here a new action of taurine that consists of a long-lasting potentiation of synaptic transmission and is explained partially by a permanent increase in the presynaptic fiber excitability and synaptic efficacy. Although we have not presented conclusive evidence demonstrating that taurine uptake is required for this new taurine action, several indirect experimental observations led us to speculate that the taurine effect is attributable to its action on an intracellular locus. We hypothesize that intracellular taurine levels modulate $\mathrm{Na}^{+}$channels, and then taurine movements between intra- and extracellular compartments are envisaged as being physiologically relevant.

\section{REFERENCES}

Ballyk BA, Quackenbush SJ, Andrew RD (1991) Osmotic effects on the CA1 neuronal population in hippocampal slices with special reference to glucose. I Neurophysiol 65:1055-1066.

Bittar P, Muller D (1993) Time-dependent reversal of long-term potentiation by brief cooling shocks in rat hippocampal slices. Brain Res 620:181-188.

Bliss TVP, Collingridge GL (1993) A synaptic model of memory: longterm potentiation in the hippocampus. Nature 361:31-39.

Buckle PJ, Haas HL (1982) Enhancement of synaptic transmission by 4-aminopyridine in hippocampal slices of the rat. J Physiol 326:109-122.

Catterall WA (1992) Cellular and molecular biology of voltage-gated sodium channels. Physiol Rev 72:S15-S48.

Chinestra P, Diabira D, Urban NN, Barrionuevo G, Ben-Ari Y (1994) Major differences between long-term potentiation and ACPD-induced slow onset potentiation in hippocampus. Neurosci Lett 182:177-180.

Clark JA, Deutch AY, Gallipoli PZ, Amara SG (1992) Functional expression and CNS distribution of a $\beta$-alanine-sensitive neuronal GABA transporter. Neuron 9:337-348.

Davies CH, Davies SN, Collingridge GL (1990) Paired-pulse depression of monosynaptic GABA-mediated inhibitory postsynaptic responses in rat hippocampus. J Physiol 424:513-531.

Didier A, Ottersen OP, Storm-Mathisen J (1994) Differential subcellular distribution of glutamate and taurine in primary olfactory neurones. NeuroReport 6:145-148.

Franconi F, Martini F, Stendardi I, Matucci R, Zilletti L, Giotti A (1982) Effect of taurine on calcium levels and contractility in guinea-pig ventricular strips. Biochem Pharmacol 31:3181-3185.

Hamberger A, Lindroth P, Nyström B (1982) Regulation of glutamate biosynthesis and release in vitro by low levels of ammonium ions. Brain Res 237:339-350.

Hanretta AT, Lombardini JB (1986) Properties of spontaneous and evoked release of taurine from hypothalamic crude $\mathrm{P}_{2}$ synaptosomal preparations. Brain Res 378:205-215.

Hess G, Kuhnt U (1992) Presynaptic calcium transients evoked by pairedpulse stimulation in the hippocampal slice. NeuroReport 3:361-364.

Holopainen I, Kontro P, Frey HJ, Oja SS (1983) Taurine, hypotaurine, and GABA uptake by cultured neuroblastoma cells. J Neurosci Res 10:83-92.

Holopainen I, Malminem O, Kuntro P (1987) Sudium-dependent highaffinity uptake of taurine in cultured cerebellar granule cells and astrocytes. J Neurosci Res 18:479-483.

Horikoshi T, Asanuma A, Yanagisawa K, Anzai K, Goto S (1988) Taurine and $\beta$-alanine act on both GABA and glycine receptors in Xenopus oocyte injected with mouse brain messenger RNA. Mol Brain Res 4:97-105.

Hruska RE, Huxtable RJ, Yamamura HI (1978) High affinity, temperature-sensitive and sodium-dependent transport of taurine in the rat brain. In: Taurine and neurological disorders (Barbeau A, Huxtable RJ, eds), pp 109-117. New York: Raven.

Huxtable RJ (1989) Taurine in the central nervous system and the mammalian actions of taurine. Prog Neurobiol 32:471-533.

Huxtable RJ (1992) Physiological actions of taurine. Physiol Rev 72:101-163.

Huxtable RJ, Laird HE, Lippincott SE (1979) The transport of taurine in the heart and the rapid depletion of tissue taurine content by guanidinoethyl sulfonate. J Pharmacol Exp Ther 211:465-471.

Jacobson I, Sandberg M, Hamberger A (1985) Mass transfer in brain dialysis devices a new method for the estimation of extracellular amino acids concentration. J Neurosci Methods 15:262-268.

Johnson JW, Ascher P (1987) Glycine potentiates the NMDA response in cultured mouse brain neurons. Nature 325:529-531.

Kamisaki Y, Maeda K, Ishimura M, Omura H, Itoh T (1993) Effects of taurine on depolarization-evoked release of amino acids from rat cortical synaptosomes. Brain Res 627:181-185.

Kontro P, Oja SS (1981) Hypotaurine transport in brain slices: comparison with taurine and GABA. Neurochem Res 6:1179-1191.

Kontro P, Oja SS (1983) Binding of taurine to brain synaptic membranes. In: CNS receptors-from molecular pharmacology to behavior (Mandel P, De Feudis FV, eds), pp 23-34. New York: Raven.

Kuriyama K, Muramatsu M, Nakagawa K, Kakita K (1978) Modulating role of taurine on release of neurotransmitters and calcium transport in excitable tissue. In: Taurine and neurological disorders (Barbeau A, Huxtable RJ, eds), pp 201-216, New York: Raven. 
Lake N, de Roode M, Nattel S (1987) Effects of taurine depletion on rat cardiac electrophysiology: in vivo and in vitro studies. Life Sci 40:997-1005.

Lærum H, Storm JF (1994) Hippocampal long-term potentiation is not accompanied by presynaptic spike broadening, unlike synaptic potentiation by $\mathrm{K}^{+}$channel blockers. Brain Res 637:349-355.

Lerma J, Herranz AS, Herreras O, Abraira V, Martín del Río R (1986) In vivo determination of extracellular concentration of amino acids in the rat hippocampus. A method based on brain microdialysis and computerized analysis. Brain Res 384:145-155.

Lewis CA, Ahmed Z, Faber DS (1991) A characterization of glycinergic receptors present in cultured rat medullary neurons. J Neurophysiol 66:1291-1303.

Liu Q-R, López-Corcuera B, Nelson H, Mandiyan S, Nelson N (1992) Cloning and expression of a cDNA encoding the transporter of taurine and $\beta$-alanine in mouse brain. Proc Natl Acad Sci USA 89:12145 -12149.

Lombardini JB (1976) Regional and subcellular studies on taurine in rat central nervous system. In: Taurine and neurological disorders (Huxlable R, Barbeau A, eds), pp 311-326. New York: Raven.

Lombardini JB (1978) High-affinity transport of taurine in the mammalian central nervous system. In: Taurine and neurological disorders (Barbeau A, Huxtable RJ, eds), pp 119-136. New York: Raven.

Martin DL, Shain W (1979) High affinity transport of taurine and $\beta$-alanine and low-affinity transport of $\gamma$-aminobutyric acid by a single transport system in cultured glioma cells. J Biol Chem 254:7076-7084.

Nagelhus EA, Lehmann A, Ottersen OP (1993) Neuronal-glial exchange of taurine during hypo-osmotic stress: a combined immunocytochemical and biochemical analysis in rat cerebellar cortex. Neuroscience $54: 615-631$.

Namima M, Okamoto K, Sakai Y (1983) Modulatory action of taurine on the release of GABA in cerebellar slices of guinea pig. $J$ Neurochem 40:1-9.

Nicoll RA, Alger BE (1981) A simple chamber for recording from submerged brain slices. $\mathrm{J}$ Neurosci Methods 4:153-156.

Okamoto K, Sakai Y (1981) Inhibitory actions of taurocyamine, hypotaurine, homotaurine, taurine and GABA on spike discharges of Purkinje cells, and localization of sensitive sites, in guinea pig cerebellar slices. Brain Res 206:371-386.

Ottersen OP (1988) Quantitative assessment of taurine-like immunoreactivity in different cell types and processes in rat cerebellum: an electromicroscopic study based on a postembedding immunogold labelling procedure. Anat Embryol 178:407-421.

Ottersen OP, Madsen S, Meldrum BS, Storm-Mathisen J (1985) Taurine in the hippocampal formation of the Senegalese baboon, Papio papio: an immunocytochemical study with the antiserum against conjugated taurine. Exp Brain Res 59:457-462.

Palkovits M, Elekes I, Láng T, Patthy A (1986) Taurine levels in discrete brain nuclei of rats. J Neurochem 47:1333-1335.

Pasantes-Morales H, Gamboa A (1980) Effect of taurine on ${ }^{45} \mathrm{Ca}^{2+}$ accumulation in rat brain synaptosomes. J Neurochem 34:244-246.

Pasantes-Morales H, Dominguez L, Montenegro J, Morán J (1988) A chloride-dependent component of the release of labeled GABA and taurine from the chick retina. Brain Res 459:120-130.

Qian N, Sejnowski T (1990) When is an inhibitory synapse effective? Proc Natl Acad Sci USA 87:8145-8149.

Satoh H (1994) Cardioprotective actions of taurine against intracellular and extracellular calcium-induced effects. Adv Exp Med Biol 359:181-196.

Sebring LA, Huxtable RJ (1985) Taurine modulation of calcium binding to cardiac sarcolemma. J Pharmacol Exp Ther 232:445-451.

Staley KJ, Mody I (1992) Shunting of excitatory input to dentate gyrus granule cells by a depolarizing $\mathrm{GABA}_{\mathrm{A}}$ receptor-mediated postsynaptic conductance. J Neurophysiol 68:197-212.

Taber KH, Lin C-T, Lju J-W, Thalmann R, Wu J-Y (1986) Taurine in hippocampus: localization and postsynaptic action. Brain Res 386:113-121.

Torp R, Haug FM, T $\phi$ nder N, Zimmer J, Ottersen OP (1992) Neuroactive amino acids in organotypic slice cultures of rat hippocampus: an immunocytochemical study of the distribution of GABA, glutamate, glutamine and taurine. Neuroscience 46:807-823.

Walberg F, Ottersen OP, Rinvik E (1990) GABA, glycine, aspartate, glutamate and taurine in the vestibular nuclei: an immunocytochemical investigation in the cat. Exp Brain Res 79:547-563.

Zalutsky RA, Nicoll RA (1990) Comparison of two forms of long-term potentiation in single hippocampal. Science 248:1619-1624.

Zeise M (1985) Taurine on hippocampal slices: comparison to GABA and glycine, and antagonism by 4-aminopyridine. In: Taurine: biological actions and clinical perspectives (Oja SS, Ahtee L, Kontro P, Paasonen MK, eds), pp 281-287. New York: Liss. 